\title{
The Resource Supply of Innovation and Investment Strategies of the Microeconomic Systems Modernization in the Conditions of Digitalization
}

\author{
SVITLANA TULCHYNSKA \\ Department of Economics and Entrepreneurship \\ National Technical University of Ukraine "Igor Sikorsky Kyiv Polytechnic Institute" \\ Kyiv, UKRAINE \\ OLHA POPELO \\ Department of Management and Civil Service \\ Chernihiv Polytechnic National University \\ Chernihiv, UKRAINE \\ OLHA VOVK \\ Department of Air Transport Economics \\ National Aviation University \\ Kyiv, UKRAINE \\ BOGDAN DERGALIUK \\ Department of Economics and Entrepreneurship \\ National Technical University of Ukraine "Igor Sikorsky Kyiv Polytechnic Institute" \\ Kyiv, UKRAINE \\ IRYNA KREIDYCH \\ Department of the Theoretical and Applied Economics \\ National Technical University of Ukraine "Igor Sikorsky Kyiv Polytechnic Institute" \\ Kyiv, UKRAINE \\ TETIANA TKACHENKO \\ Department of Economics and Entrepreneurship \\ National Technical University of Ukraine "Igor Sikorsky Kyiv Polytechnic Institute" \\ Kyiv, UKRAINE
}

\begin{abstract}
Within the presented study, applied aspects of the resource provision of innovation and investment strategies for modernization of microeconomic systems in the context of digitalization are submitted. It is substantiated that the modernization of microeconomic systems is a certain activation of the potential modernization aimed at improving the efficiency of processes, technologies, management of products, services and more. Modernization challenges of microeconomic systems are implemented through strategic management of the enterprise development provided resource provision of the potential modernization. Initial conditions of the resource provision of the microeconomic systems modernization in the conditions of digitalization are singled out, which include: efficiency; availability and clarity of the algorithm analysis formed by information base and tools; clear calculations of the cost of attracting resources to the modernization process; forecasting and assessing the risks of incomplete implementation of modernization. It is proved that in the methodological support of resource management of microeconomic systems in the design, the method of subjectivity of distributions or cost centres is used.

The methodical toolkit of the resource provision optimization of modernization designing of microeconomic systems in the conditions of digitalization with application of the competitive selection model of modernization projects for the carrying the chosen strategy of the resource supply is offered. The proposed approach to the optimization of resource provision of modernization design of microeconomic systems in the context of
\end{abstract}


digitalization involves: formation of a set of applications based on the preferential principle and priority of innovation and investment strategies; assessment of actual indicators of resource efficiency in modernization projects by each participant; decision-making on providing resources to the modernization project; determining the completeness and redundancy of the resource allocation between projects; distribution of residual resources.

Key-Words: - investment strategy, innovation strategy, resource provision, microeconomic system, modernization, capacity building, enterprise, strategic management, investment activity, innovative development.

Received: December 12, 2020. Revised: July 9, 2021. Accepted: July 17, 2021. Published: July 26, 2021.

\section{Introduction}

In modern conditions of digitalization, innovative direction of the economic systems modernization of different level acquires great value. Modernization in the direction of innovation at the microeconomic systems' level provides an opportunity to increase competitiveness and an opportunity to become market leaders.

According to the authors, the modernization of microeconomic systems in the context of digitalization is a certain activation of modernization potential aimed at improving the efficiency of processes, technologies, managing the competitiveness of products, services and more. Modernization of microeconomic systems in the context of digitalization is aimed at optimal adjustment of resource flows and maximum use of potential opportunities. In addition, in terms of digitalization, the main directions of modernization of microsystems include the formation of innovative and creative environment in terms of the social information development, which should be able to ensure high communication, as well as optimality and synergy of the internal structure of microeconomic systems.

Modernization challenges of microeconomic systems are carried out through strategic management of the enterprise development, provide the resource provision and modernization potential. Strategic management in relation to the modernization potential of microeconomic systems is aimed at its formation and activation, which involves the transformation of resources into results and specific competitive advantages. The formation and implementation of modernization potential is implemented through the activation of available resources and their systematic distribution in the processes of resource provision of innovation and investment strategies for modernization. In turn, this is due to resource efficiency and innovative strategies for the microeconomic systems modernization. Thus, in the context of digitalization, the activation of modernization potential should be based on the strategic resource provision, which necessitates research and justification of the choice in the resources allocation between innovation and investment strategies for modernization of microeconomic systems in the context of digitalization.

\section{Literature review}

Many scientists have devoted their research to the study of various issues of system modeling and development of the models of investment resources, as well as investment support processes, including: Balashov E., Kirillova A. (2021) [1]; Doskaliyeva B.B., Orynbassarova Y.D., Omarkhanova Z.M. (2016) [2]; Dubyna M., Zhavoronok A., Kudlaieva N., Lopashchuk I. (2021) [3]; Kharchenko Y., Khanin S. (2021) [4]; Lakhno V.A., Kartbayev T.S., Turginbayeva A.A. (2020) [5]; Legaspi M.E.I., Manalo M.B.P., Opeña J.B., Pempiña E.B. (2020) [6]; Lei Z. (2020) [7]; Li X., Sun Y. (2020) [8]; Ozerova M.G., Sharopatova A.V. (2021) [9]; Revko A., Butko M. (2020) [10]; Rothenberg F., Braun S., Zimmermann F. (2020) [11]; Ryutin V.S., Matveeva M.V. (2020) [12]; Shkarlet S., Ivanova N., Zhuk O. (2020) [13]; Shtyrhun K. (2020) [14]; Shynkaruk L., Ivanchenkova L., Kychko I. (2020) [15]; Zakharin S., Stoyanova-Koval S. (2021) [16]; Zhang H., Zhao H., Li H. (2020) [17].

The purpose of the study of the scientists from Kazakhstan Doskaliyeva B.B., Orynbassarova Y.D., Omarkhanova Z.M., Karibaev Y.S. and Baimukhametova A.S. is to determine the specific features of the mechanism of investment regulation, aimed at ensuring the effective implementation of projects in the context of industrial and innovative development of Kazakhstan. A system of general scientific and special research methods was used to reveal processes and phenomena in their relationship and development [2]

Within the of Balashov E. and Kirilova A., problems of increasing the share of the investment 
component in utility tariffs, as well as such factors as deductions from profits (with their financial stability), borrowing, sale of bonds and systematic audit of their production and economic activities, increasing the transparency of costs, are studied. The need to combine a large number of separate sectorial documents on the utility sector into a single law that will regulate and establish general regulatory and methodological principles of tariff formation and make this process more transparent is noted [1].

The paper of Ozerova M.G. and Sharopatova A.V. considers the problem of investing in fixed capital of agriculture. In this regard, the priority is to identify sources of funding and forms of investment support for the development in major sectors of agriculture. In order to improve investment support for the development of agricultural companies, the authors proposed to form a mechanism for attracting investment [9].

The aim of the study of the scientists from Germany Rothenberg F., Braun S., Zimmermann F., Keles D. and Fichtner W. is to present a method of using the control model to find an investment solution that can take into account such risk factors in the country as social acceptance and key factors affecting the electricity market, such as existing capacity and fuel prices. According to the results of the study, it was concluded that solar photovoltaics suffers more from cannibalization of prices, and Spain has a great unrealized potential for market investment in solar photovoltaics [11].

Within article of Lakhno V.A., Kartbayev T.S., Turginbayeva A.A., Alimseitova Z.K. and Beketova G.S. the issue is argued that in order to increase the reliability of recommendations for the evaluation of investment projects, it is necessary to make greater use of computer decision support systems. The authors proposed a general methodology for conducting research stages and using necessary mathematical tools to evaluate investment projects in the field of the enterprises' difitalization [5].

Within the paper of Ryutin V.S. and Matveeva M.V., the effectiveness of public policy to attract private investment in the heat supply industry and to build a model for optimizing sources of funding for investment activities of heat supply companies is analyzed [12].

Chinese scientists Zhang H., Zhao H., Li H., Chen Y., Ai J. and Wang Q. note that it is important to use the decision of the support system for investment in premium energy with the ability to flexibly query, to analyze, process, and assist in decision-making process. The authors prove the feasibility and effectiveness of the premium decision support system for energy efficient investments, which is successfully used in a certain area of South China [17].

The object of research of Lei Z. from China is data on investments related to the Internet and ecommerce. The author studies the theory and the method of assessing the quality of investment decisions at home and abroad, as well as they put forward a model for predicting the quality of decision-making based on the algorithm of deep learning, which aims to support a decision-making policy for investors. Based on this model of deep learning, various data of enterprise indices that can help investors in decision-making are analyzed [7].

The researchers from Manila Legaspi M.E.I., Manalo M.B.P., Opena I.B., Pempina E.B., Solomo M.V.S. and Yadao D.A. aim to develop an investment system based on the Internet and can help investors find the best poultry or pig farm that can return the best return on investment. The main functions of the system include account management, enhanced decision-making, profit maximization through the analysis of return on investment based on the production data and the profile of farmers [4].

The authors $\mathrm{Li} \mathrm{X}$. and Sun $\mathrm{Y}$. argue that compared to the developed Western capital market, the main strategy of smart investment in China's current stock market still has some shortcomings. The authors propose a predictable model that combines kernel parameters and at the same time optimizes parameters with the model. Within the article, a well-trained model for planning a smart investment plan is used [8].

\section{Methodology}

The methodological basis of the study of resource processes of innovation and investment strategies for modernization of microeconomic systems in the context of digitalization are general scientific methods of scientific knowledge and special methods of economic research based on modern technologies for designing intelligently digitized systems and management decision optimization processes. In conducting research, methods of analysis and synthesis were used - to establish patterns and to justify the direction of innovation and investment strategies in the context of digitalization; decomposition - to analyze the existing mechanisms for selecting the resource supply system and approaches to optimizing the directions of their application in modernization processes; economic and mathematical modeling, methods of normalization of indicators and linear integer - to build a model of optimization of 
resource provision according to the established criteria. Given the developed methodological basis and the existing requests for formalization of tools to justify the implementation of resource provision in the innovation and investment strategy of modernization in the context of digitalization, we consider it appropriate to justify methodological tools for optimizing resource supply of modernization design in enterprises.

\section{Results}

In the existing methodological framework, the efficiency of the resource use is usually investigated by financial statements, the results of cost analysis or working capital. Resource provision is the first level of management of modernization potential and the first stage of selection of innovation and investment strategies. Therefore, we assume that the initial conditions for resource provision of the modernization process of microeconomic systems are:

- efficiency: should be evaluated not only in the context of profitability of implemented projects, but also at the initial stages of activation. The effectiveness of resource conservation measures and the priority of optimization measures with the selection of resource-efficient projects should be analyzed;

- availability and clarity of analysis algorithms,

- formed information base and informationdigital tools;

- modernization projects must contain all necessary information and calculations on the cost of attracting resources to the modernization process. It is also necessary to assess the alternative use of resources. This will speed up decision-making to activate the reserves of modernization potential;

- forecasting and assessment of risks of incomplete implementation of modernization, unexpected obstacles to attracting resources to the modernization project.

Today in the methodological support of enterprise resource management there are many classification approaches to determining the methods or mechanisms of distribution. The design uses either the method of subjectivity of distributions or cost centers. In the first method, the decision is made by the manager and it is based on the tasks or strategies of the enterprise. In the second case, resources are allocated on a functional basis.

The first approach is more common, it uses the following methods and approaches: linear programming, resource allocation matrix; grid models; expert methods and their modifications, etc.
The distribution of resources by functional areas of the project is used at the stages of project planning of the modernization process. But when allocating in case of the resources lack, it has one drawback: it does not take into account the peculiarities of ensuring the completeness and efficiency of the resource use. Therefore, in most cases it is better to use the second approach - the distribution of contractors, areas of implementation of the modernization project. This approach is characterized by the following methods and models:

1. Models of linear programming. For example, a transport and logistics task estimates the cost of time or money to transport a distributed resource.

2. Methods of expert assessment of the importance of the implemented modernization potential.

3. Priority models - the distribution is based on the priority of the chosen strategy. There are three types of priority mechanisms: direct priorities, inverse priorities and absolute priorities.

4. Competitive mechanism - the distribution occurs in descending order of the effectiveness of the applied strategies or projects for the individual resources modernization. That is, resources are optimized on an objective basis at the time of evaluation. In addition, it is not manipulated: performers cannot influence the allocation of resources due to the availability of a sound decision and established priority.

Today, in the context of digitalization, there are many digital and information software technologies for resource allocation in the project. They are represented by specialized systems for evaluating design solutions. The first group of methods focuses on the system and scale of the analysis of economic systems, such as enterprises. Such systems include optimization digital programs CRV, MLP, LP of various modifications and other digitized logistics models. The problem with the use of such systems is their cost and the need to have special skills. In addition, in activating modernization potential, these digital programs are focused on optimizing production resources and processes. They do not have management units for forecasting investment risks or projecting future cash flows.

The group of design decision-making systems includes digital products: Microsoft Office Project, Primavera, Project Expert, Trello, OpenProj, etc. These systems allow for automated management of investment activities, the formation of team tasks or control over the implementation of strategies for the enterprise modernization. However, they do not use software to justify resource allocation decisions. They accumulate information for decision-making, 
formalization of the project implementation scenarios. That is, the decision-making function is left to a man, not artificial intelligence. In addition, project management software cannot optimize upgrade project resources on its own. The contractor sets key optimization parameters for the system: time, cost centers, limited resources or the scale of projects.

Let's consider designing the distribution of resources between projects for the implementation of innovation and investment strategies for modernization in the context of digitalization on the example of enterprises in the infrastructure sector of economy. Such microeconomic systems have a state or communal form of ownership.

Competitive conditions for the operation and attraction of external resources for modernization occurs through a public procurement and bidding system - Prozzoro. This system determines the initial competitive requirements for the executors of modernization projects and reflects the market proposals for the priority of projects for the modernization of infrastructure facilities in the context of digitalization.

In view of the above, we propose to apply the model of competitive selection of strategies and modernization projects for the implementation of resource provision in the context of digitalization (Fig. 1).

The first stage of decision-making on the provision of resources for the modernization process at the enterprises of the infrastructure sphere is to form a set of applications based on the preferential principle and priority of innovation and investment strategies.

The number of participants will be taken as $\mathrm{i}(\mathrm{i}=$ $(1, n))$, the declared volumes of resources $r$ $\{\mathrm{r} 1, \ldots \mathrm{rn}\}$, the declared indicators of efficiency of the resources use in Eri modernization projects for each participant $\{\mathrm{Er} 1, \ldots \mathrm{Ern}\}$.

It should be noted that the stated volumes and efficiency of the resource in modernization projects will be used to justify, to distribute and to actualize the effectiveness of individual participants.
This influences the decision on the priority of providing a resource for the implementation in the modernization of a particular department or facility. The amount of resources provided should be adjusted to the actual project costs.

We propose to indicate the effectiveness of the participants of the Eri in accordance with their selfanalysis from 0 to $100 \%$. This will further motivate responsibility and personal development. We also recommend using software to design schedules, control boundaries, sequences of tasks and the number of works to be performed by bidders. Such applications can be Microsoft Office Project, Project Expert, Trello, etc.

In the second stage, the actual indicators of the resource efficiency $\{$ Ef1,... Efn $\}$ in modernization projects are evaluated by each participant. In practice, the so-called "design triangle" of indicators is used in the design - compliance with the deadlines, the cost of the project and the work content within the project task.

The calculation of the actual indicator of resource efficiency in the modernization project is based on the following relative deviations, expressed as a percentage:

- TIri - in terms of implementation stage of the modernization project. The indicator is calculated as the ratio of the difference between the actual time spent and the planned time spent to the actual time of work;

- CPri - at the cost of the modernization project stage: is defined as the ratio of the difference between the cost of the developed resource and the actual costs to the cost of the developed amount of resources;

- ACri - according to the content of works at the stage: it is estimated according to the data from the plan of management of the content of works of the project (or the checklist of works of the project). It is defined as the ratio of the difference between the planned number of works of the contractor and the number of project works to the difference between the number of works that the contestant planned to perform within the study stage. 


\begin{tabular}{|c|c|}
\hline $\begin{array}{l}\text { Stage V: distribution of resources } \\
\text { between project selection leaders. }\end{array}$ & $\begin{array}{l}\text { Projects are ranked in descending order of efficiency: } \\
E_{f e} l>E_{f e} 2>\ldots>E_{f e} k \text { and there is a distribution of residual resources } M \\
\text { between them. }\end{array}$ \\
\hline $\begin{array}{l}\text { Stage IV: optimization of the solution } \\
\text { according to the completeness criteria } \\
\text { and without residual allocation of } \\
\text { resources between modernization } \\
\text { projects }\end{array}$ & 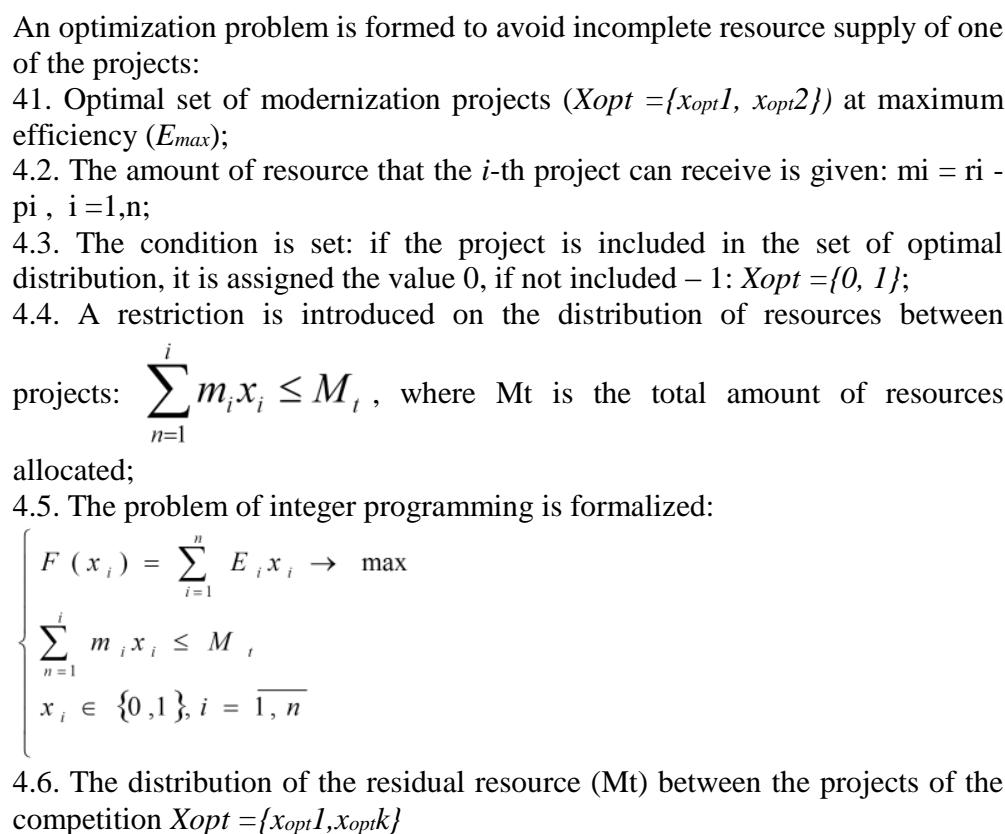 \\
\hline
\end{tabular}

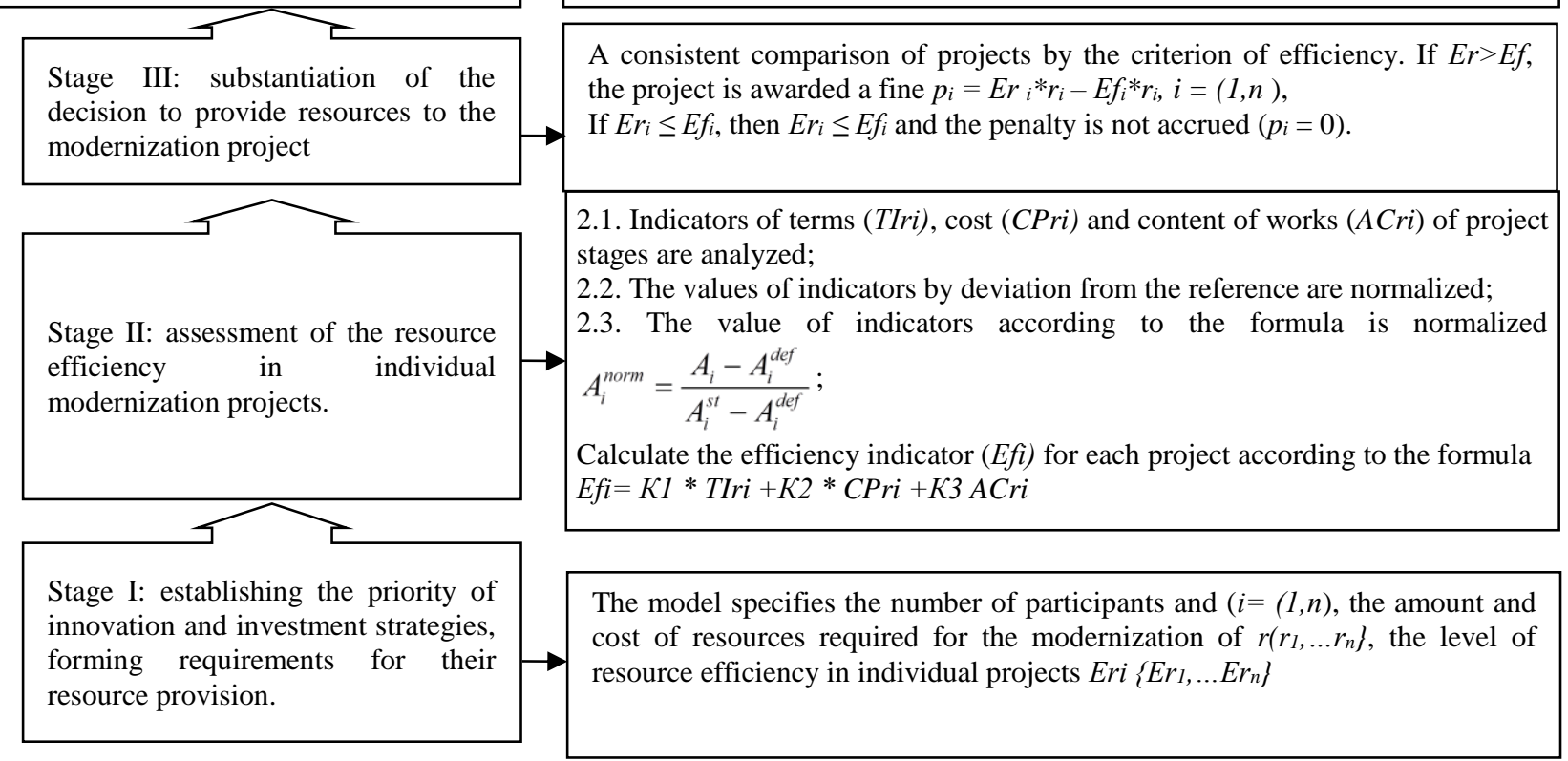

Figure 1: Scheme of the competitive selection of projects for the resource provision of innovation and investment strategies of modernization in the conditions of digitalization

Source: built by the authors

In order to further apply the described parameters in the model in calculating the efficiency of modernization, they must be normalized: if $A_{i}^{\text {st }}=$ $100 \%$ - the reference value of the described parameters, then $A_{i}{ }^{d e f}=-100 \%$ - defective value, $A_{i}$ - the obtained value. Rationing is carried out using the following formula:

$$
A_{i}^{\text {norm }}=\frac{A_{i}-A_{i}^{\text {def }}}{A_{i}^{\text {st }}-A_{i}^{\text {def }}}
$$

where $A_{i}^{\text {norm }}$ is the normalized value of the efficiency indicator of the bidder for the resource supply of the modernization project, $A_{i}{ }^{\text {norm }} 0[01]$.

According to the obtained data, the Efi efficiency indicator is calculated for each contestant according to the formula:

$$
E f i=K 1 * T I r i+K 2 * C P r i+K 3 \text { ACri }
$$


where $\mathrm{K} 1, \mathrm{~K} 2$ and $\mathrm{K} 3$ are weight coefficients of parameters that have an index expression and are equal to one in the sum.

The value of efficiency indicators $E f i=\left[\begin{array}{ll}0 & 1\end{array}\right]$.

If the value of $E f i=0.5$, then the implementation stage of the modernization project will be performed clearly according to the planned terms, cost and scope of work.

The third stage of decision-making on the provision of resources to the modernization project is a consistent comparison of actual and declared performance indicators of bidders. If $E r>E f$, then a fine of $p_{i}$ is introduced:

$$
p_{i}=E r_{i} * r_{i}-E f_{i} * r_{i}, i=(1, n)
$$

For the final analysis, we set the final value of the effectiveness of the $E_{f e}$ contestant:

$$
E_{f e}=E f_{i}
$$

If $E r_{i} \leq E f_{i}$, then $E_{f e}=E r_{i}$ and the penalty is not accrued $\left(p_{i}=0\right)$.

At the fourth stage of the objects selection of modernization changes the completeness and redundancy of distribution of resources between projects of the implementation of innovation and investment strategies for the modernization in the conditions of digitalization is defined. The problem in this optimization is the lack of resources for one of the projects. Moreover, this leads to a loss of efficiency and results from the use of residual resources. Therefore, we introduce an optimization problem for complete and efficient allocation of resources between modernization projects.

The optimization problem is formulated as follows: let there be a given amount of resource that each participant can receive when optimizing the distribution:

$$
m_{i}=r_{i}-p_{i}, \quad i=1, n,
$$

where, $m_{i}$ is the amount of resource that the $\mathrm{i}$-th draft project can receive.

Complex indicators of $E_{f e}$ efficiency are given. It is necessary to find $X o p t=\left\{x_{o p t} 1, x_{o p t} 2\right\}$ - the optimal set of modernization projects, among which there will be a residual resource allocation to achieve maximum efficiency Emax with optimal resource allocation. If the modernization project is included in the set of optimal distribution, it is assigned the value 0 , if not included - 1 :

$$
X o p t=\{0,1\}
$$

Next, a restriction on the distribution of resources between competing projects is introduced:

$$
\sum_{n=1}^{i} m_{i} x_{i} \leq M t
$$

where $M t$ is the total amount of resource allocated.

Thus, to determine the optimal set of projects for the implementation of modernization strategies, among which there is a residual allocation of resources, the problem of integer programming is formalized:

$$
\begin{gathered}
F\left(x_{i}\right)=\sum_{i=1}^{n} E_{i} x_{i} \rightarrow \max \\
\sum_{n=0}^{i} m_{i} x_{i} \leq M_{t} \\
x_{i} \in\{0,1\}, i=\overline{1, n}
\end{gathered}
$$

After finding an optimized set of contestants and modernization strategies, further distribution of residual resources will be implemented between these contestants Xopt $=\left\{x_{o p t} 1, x_{o p t} k\right\}$. Thus, it is not only fashionable to avoid the loss of the incomplete resource supply of residual projects, but also increases the effectiveness of implemented strategies or projects.

At the last stage of the resource provision of the modernization process there is a distribution of residual resources $M$ between the leaders of the ranked order of the contestants in descending order of their performance indicators:

$$
E_{f e} 1>E_{f e} 2>\ldots>E_{f e} k
$$

Thus, the application of a competitive model of the modernization project selection for the implementation of innovation and investment strategy of modernization in terms of digitization on the basis of efficiency, not only ensures optimal resource allocation, but also adheres to the principles of waste and efficiency.

To test the application of the proposed method of selection of modernization projects, we will perform calculations on the example of modernization processes of enterprises of infrastructure economy.

Conditions of resource provision and efficiency of its distribution between five projects on modernization of the vehicle are established at the level of its cost in $250000 \mathrm{UAH}$ that is presented in Tab. 1. Let's assume that the cost of the existing modernization potential of the enterprise is 780,000 $\mathrm{UAH}$, and the need for vehicles -3 units. 
Table 1: Initial conditions for the resources allocation for the modernization of the enterprise infrastructure in the context of digitalization

\begin{tabular}{|l|c|c|c|c|c|}
\hline Participants - projects to modernize the vehicle & $\mathbf{1}$ & $\mathbf{2}$ & $\mathbf{3}$ & $\mathbf{4}$ & $\mathbf{5}$ \\
\hline $\begin{array}{l}\text { Volume of necessary resources for the project } \\
\text { implementation, thousand UAH }\end{array}$ & 250,00 & 250,00 & 250,00 & 250,00 & 250,00 \\
\hline Declared level of resource efficiency in projects, $\%$ & 80,00 & 90,00 & 80,00 & 90,00 & 90,00 \\
\hline Normalized deadlines, units & 0,95 & 0,99 & 0,99 & 0,95 & 0,95 \\
\hline Normalized project cost, units & 0,65 & 0,95 & 0,89 & 0,52 & 0,90 \\
\hline Normalized content of works, units & 0,65 & 0,80 & 0,74 & 0,25 & 0,85 \\
\hline $\begin{array}{l}\text { Actual indicator of resource efficiency in projects, } \\
\text { units }\end{array}$ & 0,71 & 0,91 & 0,87 & 0,53 & 0,90 \\
\hline Fine, thousand UAH & 22,50 & 0,00 & 0,00 & 93,75 & 0,00 \\
\hline
\end{tabular}

Source: compiled by the authors.

Table 1 presents the conditions for determining the effectiveness of attracting resources to projects for the implementation of innovation and investment strategies for modernization in terms of digitalization and the formation of conditions for their competitive selection. Given the obtained data, we can see that projects No. 1 and No. 4 have lower resource efficiency than stated in the project. Therefore, fines are calculated for these projects the amount by which the application for resources is reduced.

According to Figure 1, we will optimize the supply of resources and projects (Table 2).

Table 2: Optimization of resources and projects in the implementation of innovation and investment strategy of modernization in the context of digitalization

\begin{tabular}{|l|c|c|c|c|c|}
\hline Participants - projects to modernize the vehicle & $\mathbf{1}$ & $\mathbf{2}$ & $\mathbf{3}$ & $\mathbf{4}$ & $\mathbf{5}$ \\
\hline Final value of the contestant's efficiency, units & 0,00 & 0,91 & 0,87 & 0,00 & 0,90 \\
\hline Amount of resources that the project can receive, thousand UAH & 227 & 250 & 250 & 156 & 250 \\
\hline $\begin{array}{l}\text { Modernization project included in the set of optimal distribution (by binary } \\
\text { distribution) }\{0 ; 1\}\end{array}$ & 0 & 1 & 1 & 0 & 1 \\
\hline Restrictions on the resources distribution between projects, thousand UAH & 0 & 250 & 250 & 0,00 & 250 \\
\hline Ranking of projects indicating the final efficiency, units & 0,00 & 1,00 & 3,00 & 0,00 & 2,00 \\
\hline Additional distribution of residual resource, thousand UAH & 0,00 & 20,00 & 0,00 & 0,00 & 0,00 \\
\hline Cost of received resources for projects, thousand UAH & 0 & 270 & 250 & 0 & 250 \\
\hline
\end{tabular}

Source: compiled by the authors.

Thus, the analysis showed that the given conditions of project efficiency and resource supply affect the results of competitive selection. In addition, adherence to the principles of zero-waste and optimality in terms of resources, terms and scope of work in modernization projects allows them to rank and increase the potential for the introduction of innovative technologies. This is achieved by rationalizing residual resources and eliminating inefficient projects.

The principle of the efficiency level is important in the context of ensuring the effectiveness of the modernization project or strategy. Then in the time period of the consumption and implementation of modernization projects is uneven. In addition, before the distribution it is necessary to analyze the purpose of resources: if the financial resource is the most mobile, the specifics of the use of labor or production resources should be specialized and justified.

\section{Conclusion}

The formation of methodological tools for the resource provision of innovation and investment strategies of modernization in the context of digitalization is based on the cognitive analysis and economic-mathematical modeling. This implements the goals of the modernization potential development and innovative renewal of microeconomic systems in the conditions of digitalization. Microeconomic systems can justify the choice of modernization strategies and projects. At a choice efficiency, optimality of a strategic set is provided. Moreover, the proposed tools for optimizing resource provision allows to ensure complete activation of resources and the needs of individual innovation and investment strategies. 
The scientific novelty of this study includes the methodological tools developed by the authors to optimize the resource supply of modernization design of microeconomic systems in the context of digitization using the model of competitive selection of modernization projects to implement innovation and investment strategies of the resource supply. The principle and priority of innovation and investment strategies; assessment of actual indicators of resource efficiency in modernization projects by each participant; consistent comparison of actual and declared performance indicators of projects; determining the completeness and redundancy of the resource allocation between projects; distribution of residual resources between the leaders of the ranked order of the contestants in descending order of their performance indicators.

The practical significance of the proposed methodological tools for optimizing the resource supply of modernization design of microeconomic systems in terms of digitization using the model of competitive selection of modernization projects to implement innovation and investment strategies of resource provision allows microeconomic systems to optimize resource allocation. And, to increase efficiency of modernization in the conditions of digitalization.

Further scientific research requires the improvement of methodological tools to ensure the effectiveness of investment and innovation strategies in the context of digitalization.

\section{References:}

[1]. Balashov, E., Kirillova, A. (2021). Tariff policy and investment support for the modernization of the public utility infrastructure of the municipality. XXII International Scientific Conference Energy Management of Municipal Facilities and Sustainable Energy Technologies (EMMFT-2020), 244, 06004. https://doi.org/10.1051/e3sconf/202124406004.

[2]. Doskaliyeva, B.B., Orynbassarova, Y.D., Omarkhanova, Z.M., Karibaev, Y.S., Baimukhametova, A.S. (2016). Development of the system of investment support of projects in the industrial - Innovative development of Kazakhstan. International Journal of Environmental and Science Education, 11(12), 5109-5127. https://files.eric.ed.gov/fulltext/EJ1115629.pdf.

[3]. Dubyna, M., Zhavoronok, A., Kudlaieva, N., Lopashchuk, I. (2021). Transformation of household credit behavior in the conditions of digitalization of the financial services market. Journal of Optimization in Industrial Engineering, 14(1), pp. 97-102.

[4]. Popelo, O., Tulchynska, S., Kharchenko, Y., Dergaliuk, B., Khanin, S., Tkachenko, T. (2021).
Systemic Approach to Assessing Sustainable Development of the Regions. Journal of Environmental Management and Tourism, (Volume XII, Summer), 3(51), pp. 742-753. DOI: 10.14505//jemt.12.3(51).13.

[5]. Lakhno, V.A., Kartbayev, T.S., Turginbayeva, A.A., Alimseitova, Z.K., Beketova, G.S. (2020). Analysis of existing and development prospects of decision support systems for evaluating investment projects in the field of enterprise digitalization. International Journal of Advanced Trends in Computer Science and Engineering, 9(5), 8533-8539. http://www.warse.org/IJATCSE/static/pdf/file/ijatcse 233952020.pdf.

[6]. Legaspi, M.E.I., Manalo, M.B.P., Opeña, J.B., Pempiña, E.B., Solomo, M.V.S., Yadao, D.A. (2020). Project investocks: Online investment system for poultry and swine raisers with decision support system. International Journal of Scientific and Technology Research, 9(4), 1328-1331. https://www.ijstr.org/final-print/apr2020/ProjectInvestocks-Online-Investment-System-For-PoultryAnd-Swine-Raisers-With-Decision-SupportSystem.pdf.

[7]. Lei, Z. (2020). Research and analysis of deep learning algorithms for investment decision support model in electronic commerce. Electronic Commerce Research, 20(2), 275-295. DOI:10.1007/s10660-01909389-w.

[8]. Li, X., Sun, Y. (2020). Stock intelligent investment strategy based on support vector machine parameter optimization algorithm. Neural Computing and Applications, 32(6), 1765-1775. https://doi.org/10.1007/s00521-019-04566-2.

[9]. Ozerova, M.G., Sharopatova, A.V. (2021). Investment support for the development of agriculture in the region. IOP Conference Series: Earth and Environmental Science, 677(2), 022082.

[10]. Revko, A., Butko, M., Popelo, O. (2020). Methodology for Assessing the Inflence of Cultural Infrastructure on Regional Development in Poland and Ukraine. Comparatie Economic Research. Central and Eastern Europe, 23(2), pp. 21-39.

[11]. Rothenberg, F., Braun, S., Zimmermann, F., Keles, D., Fichtner, W. (September 2020). Investment decision support for zero subsidy wind and solar An optimization based simulation approach. International Conference on the European Energy Market, EEM, 9221884.

[12]. Ryutin, V.S., Matveeva, M.V. (2020). Organization of investment support for entrepreneurial activity in energy construction. IOP Conference Series: Materials Science and Engineering, 880(1), 012102.

[13]. Shkarlet, S., Ivanova, N., Popelo, O., Dubina, M., Zhuk, O. (2020). Infrastructural and Regional Development: Theoretical Aspects and Practical Issues. Studies of Applied Economics, 38-3(1).

[14]. Shkarlet, S., Dubyna, M., Shtyrhun, K. (2020). Transformation of the Paradigm of the Economic Entities Development in Digital Economy. WSEAS 
TRANSACTIONS on ENVIRONMENT and DEVELOPMENT, 16, pp. 413-422.

[15]. Shynkaruk, L., Ivanchenkova, L., Kychko, I., Kartashova, O., Melnyk, Y., Ovcharenko, T. (2020). Managing the economy's investment attractiveness of the state as a component of international business development. International Journal of Management (IJM), 11 (5), pp. 240-251.

[16]. Zakharin, S., Stoyanova-Koval, S., Kychko, I., Marhasova V., Shupta I. (2021). Strategic Management of the Investment Process in the Agricultural Sector (for Example, Agricultural Enterprises and the Food Industry). Journal of Optimization in Industrial Engineering (JOIE), 14(1), pp. 209-218. URL: http://www.qjie.ir/article_677867.html.

[17]. Zhang, H., Zhao, H., Li, H., Chen, Y., Ai, J. (2020). A Decision Support System of Premium Power Supply Investment. Proceedings 2020 5th Asia Conference on Power and Electrical Engineering, ACPEE $2020 \quad$ (pp. 934-939). DOI:10.1109/ACPEE48638.2020.9136300.

\section{Creative Commons Attribution}

\section{License 4.0 (Attribution 4.0 \\ International, CC BY 4.0)}

This article is published under the terms of the Creative Commons Attribution License 4.0 https://creativecommons.org/licenses/by/4.0/deed.en US 